\title{
Valuing ecological systems and services
}

\section{Robert Costanza ${ }^{1}$, Ida Kubiszewski ${ }^{1}$, David Ervin ${ }^{1,2,3}$, Randy Bluffstone ${ }^{3}$, James Boyd ${ }^{4}$, Darrell Brown ${ }^{1,5}$, Heejun Chang ${ }^{1,6}$, Veronica Dujon ${ }^{7}$, Elise Granek ${ }^{1,2}$, Stephen Polasky ${ }^{9}$, Vivek Shandas ${ }^{1,8}$ and Alan Yeakley ${ }^{2}$}

\begin{abstract}
Addresses: ${ }^{1}$ Institute for Sustainable Solutions, Portland State University, Mail code: SUST, P.O. Box 751, Portland, OR 97207, USA ${ }^{2}$ Department of Environmental Science and Management, Portland State University, P.O. Box 751, Portland, OR 97207, USA; ${ }^{3}$ Department of Economics, Portland State University, PO Box 751, Portland, OR 97207, USA; ${ }^{4}$ Resources for the Future, 1616 P Street NW, Washington, DC 20036, USA; ${ }^{5}$ School of Business Administration, Portland State University, P.O. Box 751, Portland, OR 97207, USA; ${ }^{6}$ Department of Geography, Portland State University, PO Box 751- GEOG, Portland, OR 97207, USA; ${ }^{7}$ Department of Sociology, Portland State University, P.O. Box 751, Portland, OR 97207, USA; ${ }^{8}$ Department of Urban Studies and Planning, Portland State University, P.O. Box 751-USP, Portland, OR 97207, USA; ${ }^{9}$ Department of Applied Economics and Department of Ecology, Evolution, and Behavior, University of Minnesota, 1994 Buford Avenue, St. Paul, MN 55108, USA

*Corresponding author: Robert Costanza (robert.costanza@pdx.edu)

FI000 Biology Reports 2011, 3:14 (doi:10.3410/B3-14)

This is an open-access article distributed under the terms of the Creative Commons Attribution-Non Commercial License (http://creativecommons.org/licenses/by-nc/3.0/legalcode), which permits unrestricted use, distribution, and reproduction in any medium, provided the original work is properly cited. You may not use this work for commercial purposes.

The electronic version of this article is the complete one and can be found at: http://fl000.com/reports/b/3//4
\end{abstract}

\begin{abstract}
Making trade-offs between ecological services and other contributors to human well-being is a difficult but critical process that requires valuation. This allows both better recognition of the ecological, social, and economic trade-offs and also allows us to bill those who use up or destroy ecological services and reward those that produce or enhance them. It also aids improved ecosystems policy. In this paper we clarify some of the controversies in defining the contributions to human well-being from functioning ecosystems, many of which people are not even aware of. We go on to describe the applicability of the various valuation methods that can be used in estimating the benefits of ecosystem services. Finally, we describe some recent case studies and lay out the research agenda for ecosystem services analysis, modeling, and valuation going forward.
\end{abstract}

\section{Ecosystem services}

"Ecosystem services" are the benefits people derive from functioning ecosystems, the ecological characteristics, functions, or processes that directly or indirectly contribute to human well-being $[1,2]$. Ecosystem processes and functions may contribute to ecosystem services, but they are not synonymous as they describe biophysical relationships (such as the carbon cycle) and exist regardless of whether or not humans benefit $[3,4]$. Ecosystem services, on the other hand, only exist if they contribute to human well-being and cannot be defined independently [5].

The ecosystems that provide the services are sometimes referred to as "natural capital," using the general definition of capital as a stock that yields a flow of services over time [6]. In order for these benefits to be realized, natural capital (natural ecosystems and their products that do not require human activity to build or maintain, such as fish stocks) must be combined with other forms of capital that do require human intervention to build and maintain. These include: built or manufactured capital (e.g., fishing boats); human capital (e.g., human labor and knowledge about how to fish); and social capital (e.g., fishing communities and cultures) [7].

These four general types of capital are all required in complex combinations to produce any and all human benefits. Ecosystem services can thus be defined as the relative contribution of natural capital to the production of human benefits, in combination with the three other forms of capital. These benefits can involve the use, 
option to use, or mere appreciation of the existence of natural capital.

The following categorization of ecosystem services has been used by the Millennium Ecosystem Assessment [2]:

(a) Provisioning services-ecosystem services that combine with built, human, and social capital to produce food, timber, fiber, or other "provisioning" benefits. For example, fish delivered to people as food require fishing boats (built capital), fisherfolk (human capital), and fishing communities (social capital) to produce.

(b) Regulating services-services that regulate different aspects of the integrated system. These are services that combine with the other three capitals to produce flood control, storm protection, water regulation, human disease regulation, water purification, air quality maintenance, pollination, pest control, and climate control. For example, the storm protection services of coastal wetlands require the wetlands and the built infrastructure, people, and communities to be protected. These services are generally not marketed but have clear value to society.

(c) Cultural services-ecosystem services that combine with built, human, and social capital to produce recreation, aesthetic, scientific, cultural identity, or other "cultural" benefits. For example, to produce a recreational benefit requires a beautiful natural asset (a lake), in combination with built infrastructure (a road, trail, dock, and so on), human capital (people able to appreciate the lake experience), and social capital (family, friends, and institutions that make the lake accessible and safe).

(d) Supporting "services" - services that maintain basic ecosystem processes and functions such as soil formation, carbon fixation, and habitat for animals. These services affect human well-being indirectly by maintaining processes necessary for provisioning, regulating, and cultural services. They also refer to the ecosystem services that have not yet been combined with built, human, and social capital to produce human benefits but nevertheless underlie these benefits. For example, net primary production is an ecosystem function that supports carbon sequestration and removal from the atmosphere, which combines with built, human, and social capital to provide the benefit of climate regulation. Some would argue that these "supporting" services should rightly be defined as ecosystem "functions", since they may not yet have interacted with the other three forms of capital to create benefits. We agree with this in principle, but recognize that supporting services/functions may sometimes be used as proxies for services in the other categories, such as when the benefits cannot be easily measured directly.

This categorization leads to a very broad definition of services, limited only by the requirement of a contribution to human well-being. Even without any subsequent valuation, explicitly listing the services derived from an ecosystem can help ensure appropriate recognition of their importance. This can help make the analysis of ecological systems more transparent and can help decision makers weigh up the relative merits of the different options before them.

\section{Valuation}

Many ecosystem services are public goods. This means that multiple users can simultaneously benefit from using them and it is difficult to exclude people from benefiting from them. This creates circumstances where analyzing individual choices is not the most appropriate way to assess an ecosystem's value and use. Instead, some form of community or group choice process is needed. As ecosystem services (being public goods) are generally not traded in markets, we need to develop other methods to assess their value.

There are a number of methods that can be used to estimate or measure benefits from ecosystems. Valuation can be expressed in several ways, including money, physical units, or indices. Economists have developed a number of valuation methods that typically use monetary units (see [8]) while ecologists and others have developed measures expressed in a variety of nonmonetary units such as biophysical trade-offs (cf. [9]) and qualitative analyses.

There are two main methods for estimating monetary values: revealed and stated preferences. Both of theses typically involve the use of sophisticated statistical methods to tease out the values [10]. Revealed preference methods involve analyzing individuals' choices in realworld settings and inferring value from those observed choices. Examples include production-oriented valuation that looks at changes in direct-use values from products actually extracted from the environment (e.g., fish trawled from the sea). This method may also be applicable to indirect-use values, such as the benefits forests provide to agricultural production by controlling soil erosion. Other revealed preference methods infer ecosystem service values from resulting changes in housing markets. For example, urban forest ecosystems and wetlands may improve water quality and that may be (partially) captured in property values [11]. The travel 
cost valuation method is used to value recreation ecosystem services based on the resources, money, and time visitors spend visiting recreation sites.

Stated preference methods rely on individuals' responses to hypothetical scenarios involving ecosystem services and include contingent valuation and structured choice experiments. Contingent valuation uses a highly structured survey methodology that asks respondents to value ecosystem improvements (e.g., better stream quality) and the ecosystem services they will generate (e.g., increased salmon stocks) [12].

Choice experiments present respondents with scenarios that embody combinations of ecosystem services and monetary costs and ask for the most preferred scenarios to infer ecosystem service values.

A key challenge in any valuation is imperfect information. Individuals might, for example, place no value on an ecosystem service if they do not know the role that the service is playing in their well-being [13]. Here is an analogy. If a tree falls in the forest and there is no one around to hear it, does it still make a sound? The answer to this old question obviously depends on how one defines "sound". If "sound" is defined as the perception of sound waves by people, then the answer is no. If "sound" is defined as the pattern of physical energy in the air, then the answer is yes. In this second case, choices in both revealed and stated preference models would not reflect the true benefit of ecosystem services. Another key challenge is accurately measuring the functioning of the system to correctly quantify the amount of a given service derived from that system (e.g., $[14,15])$.

But recognizing the importance of information does not obviate the limitations of obtaining it. As the tree analogy demonstrates, perceived value can be quite a limiting valuation criterion, because natural capital can provide positive contributions to human well-being that are either never or only vaguely perceived, or may only manifest themselves at a future time. A broader notion of value allows a more comprehensive view of value and benefits, including, for example, valuation relative to alternative goals, such as fairness and sustainability, within the broader goal of human well-being [16]. Whether these values are perceived or not and how well or accurately they can be measured are separate (and important) questions.

\section{Case studies}

\section{Early valuation syntheses}

Scientists and economists have discussed the general concepts behind natural capital, ecosystem services, and their value for decades, with some early work dating as far back as the 1920s. However, the first explicit mention of the term "ecosystem services" in the peerreviewed scientific literature was in a paper by Ehrlich and Mooney in 1983 [17]. More than 2,400 papers have been published on the topic of ecosystem services since then, according to a search of the Institute for Scientific Information's "Web of Science" database, accessed on February 22, 2011. This database includes only a subset of scientific journals and no books, so it represents only a subset of the literature on this topic. The first mention of the term "natural capital" in the scientific literature was in a paper by Costanza and Daly in 1992 [6].

One of the first studies to estimate the value of ecosystem services globally was published in Nature and entitled "The value of the world's ecosystem services and natural capital" [1]. This paper estimated the value of 17 ecosystem services for 16 biomes to be in the range of US $\$ 16-54$ trillion per year, with an average of US $\$ 33$ trillion per year, a figure larger than the annual gross domestic product (GDP) at the time. Some have argued that global society would not be able to pay more than their annual income for these services, so a value larger than global GDP does not make sense. However, not all benefits are picked up in GDP, so it should not represent a limit on real benefits [18].

In this study, estimates of global ecosystem services were derived from a synthesis of previous studies that utilized a wide variety of techniques, such as those mentioned above, to value specific ecosystem services in specific biomes (see [19] for a collection of commentaries and critiques of the methodology). This technique, called "benefit transfer", uses studies that have been done at other locations or in different contexts, but can be applied with some modification. Such a methodology, although useful as an initial estimate, is just a first cut and much progress has been made since then (cf. [20-22]).

\section{Major world reports on ecosystem services}

More recently the concept of ecosystem services gained attention with a broader academic audience and the public when the Millennium Ecosystem Assessment was published [2]. The Millennium Ecosystem Assessment was a 4-year, 1,300-scientist study commissioned by the United Nations in 2005. The report analyzed the state of the world's ecosystem services and provided recommendations for policy makers. It determined that human actions have depleted the world's natural capital to the point that the ability of a majority of the globe's ecosystems to sustain future generations can no longer be taken for granted. 
In 2008, a second international study was published on The Economics of Ecosystems and Biodiversity [23] hosted by United Nations Environment Programme. The Economics of Ecosystems and Biodiversity's primary purpose was to draw attention to the global economic benefits of biodiversity, to highlight the growing costs of biodiversity loss and ecosystem degradation, and to draw together expertise from the fields of science, economics, and policy to enable practical actions moving forward. The Economics of Ecosystems and Biodiversity report was picked up extensively by the mass media, bringing ecosystem services to a broad audience.

\section{The Ecosystem Services Partnership and ongoing work}

With such high profile reports being published, ecosystem services have entered not only the public media [24] but also into business. Just one example is the Dow Chemical Company's recently established US $\$ 10$ million collaboration with The Nature Conservancy to tally up the ecosystem costs and benefits of every business decision [25]. Such collaborations will provide a significant addition to ecosystem services valuation knowledge and techniques. However, there is significant research that is still required (see below). Our scientific institutions can help lead this process through transdisciplinary graduate education, such as the Ecosystem Services for Urbanizing Regions program funded by the National Science Foundation's Integrative Graduate Education and Research Traineeship program [26].

Hundreds of projects and groups are currently working toward better understanding, modeling, valuation, and management of ecosystem services and natural capital. It would be impossible to list all of them here, but the new Ecosystem Services Partnership [27] is a global network that does just that and helps to coordinate the activities and build consensus. The following lays out the research agenda as agreed to by a group of 30 participants at a meeting in Salzau, Germany, in June 2010, at the launch of the Ecosystem Services Partnership.

\section{Integrated measurement, modeling, valuation, and decision science in support of ecosystem services}

The scientific community needs to continue to develop better methods to measure, monitor, map, model, and value ecosystem services at several scales [28]. Ideally, these efforts should take place using interdisciplinary teams and strategies and in close collaboration with ecosystem stakeholders. Moreover, this information must be provided to decision makers in an appropriate, transparent, and viable way, to clearly identify the different outcomes of different policies (i.e., [4]). At the same time, we cannot wait for high levels of certainty and precision to act when confronting significant irreversible and catastrophic consequences. We must synergistically continue to improve the measurements with evolving institutions and approaches that can effectively utilize these measurements.

\section{Trade-offs}

Ecological conflicts arise from two sources: (a) scarcity and restrictions in the amount of ecosystem services that can be provided and (b) the distribution of the costs and benefits of the provisioning of the ecosystem services. Ecosystem services science makes trade-offs explicit and, thus, facilitates management and planning. It enables stakeholders to make sound value judgments. Ecosystem services science thus generates relevant socioecological knowledge for stakeholders and other decision makers and generates sets of planning options that can help resolve sociopolitical conflicts.

\section{Accounting and assessment}

Accounting attempts to look at the flow of materials with relative objectivity, while assessment evaluates a system or process with a goal in mind and is more normative. Both are integrating frameworks with distinctive roles. Both ecosystem service accounting and assessment need to be developed and pursued using a broader lens that includes social, economic, and ecological components. Within the broader lens we also need to balance expert and local knowledge across scales.

\section{Modeling}

We need to improve modeling to synthesize and quantify our understanding of ecosystem services and to understand dynamic, nonlinear, spatially explicit trade-offs as part of the larger socioecological systems. Stakeholders should be active collaborators in this model development and testing process to assure relevancy. These models can incorporate and aid accounting and assessment exercises and link directly with the policy process at multiple time and space scales. In particular, modeling can quantify potential shifts in ecosystem services under different environmental and socioeconomic scenarios.

\section{Bundling}

Most ecosystem services are produced as joint products (or bundles) from intact ecosystems. The relative rates of production of each service vary from system to system, site to site, and time to time. We must consider the full range of services and the characteristics of their bundling in order to prevent creating dysfunctional incentives and to maximize the net benefits to society $[29,30]$. As an illustration, focusing only on the carbon sequestration service of ecosystems may in some instances reduce the overall value of the full range of ecosystem services; for example, by reducing biodiversity. 


\section{Scaling}

Ecosystem services are relevant over a broad range of scales in space, time, governance, and complexity, including the legacy of past behavior. We need measurement, models, accounts, assessments, and policy discussions that address these multiple scales, as well as interactions, feedbacks, and hierarchies among them.

\section{Adaptive management and new institutions for ecosystem services}

Given that pervasive uncertainty always exists in ecosystem service measurement, monitoring, modeling, valuation, and management, we should continuously gather and integrate appropriate information regarding ecosystem services, with the goal of learning and adaptive improvement. To do this we should constantly evaluate the impacts of existing systems and, with stakeholder participation, design new systems to experiment with how we can more effectively quantify performance, and learn ways to better manage such complex systems to achieve social goals.

\section{Property rights}

Given the public-goods nature of most ecosystem services, we need institutions that can effectively deal with this characteristic using a sophisticated suite of property-rights regimes. We need institutions that employ an appropriate combination of private, state, and common property-rights systems to establish clear property rights over ecosystems without privatizing them. Systems of payment for ecosystem services and common asset trusts can be effective elements in these institutions.

\section{Scale-matching}

The scale of the institutions to manage ecosystem services must be matched with the scales of the services themselves. Mutually reinforcing institutions at local, regional, and global scales over short, medium, and long time scales will be required. Institutions should be designed to ensure the flow of information across scales, to take ownership regimes, cultures, and actors into account, and to fully internalize costs and benefits.

\section{Distribution}

Systems should be designed to ensure inclusion of the poor, since they are generally more dependent on common property assets like ecosystem services. Freeriding, especially by wealthier segments of society, should be deterred, and beneficiaries should pay for the services they receive from biodiverse and productive ecosystems.

\section{Information dissemination}

One key limiting factor in sustaining natural capital is lack of knowledge of how ecosystems function and how they support human well-being. This can be overcome with targeted educational campaigns that are tailored to disseminate success and failures to both the general public and officials and through collaboration among public, private, and government entities.

\section{Participation}

Relevant stakeholders (local, regional, national, and global) should be engaged in the formulation and implementation of management decisions. Full stakeholder awareness and participation not only improves ecosystem services analyses, but contributes to credible, accepted rules that identify and assign the corresponding responsibilities appropriately, and that can be effectively enforced.

\section{Science/policy interface}

Ecosystem services concepts can be an effective link between science and policy by making the trade-offs more transparent [4]. An ecosystem services framework can therefore be a beneficial addition to policy-making institutions and frameworks and to integration of science and policy.

\section{Conclusions}

Natural capital and ecosystem services are key concepts that are changing the way we view, value, and manage the natural environment. They are changing the framing of the issue away from "jobs versus the environment" to a more balanced assessment of all the assets that contribute to human well-being and their interrelationships. Significant transdisciplinary research has been done in recent years on ecosystem services, but there is still much more to do and this will be an active and vibrant research area for the coming years, because better understanding of ecosystem services is critical for creating a sustainable and desirable future. Placing credible values on the full suite of ecosystem services is key to improving their sustainable management.

\section{Abbreviation}

GDP, gross domestic product.

\section{Competing interests}

The authors declare that they have no competing interests.

\section{Acknowledgements}

We thank the Institute for Sustainable Solutions at Portland State University for supporting several of the coauthors during the preparation of this manuscript. We also thank the Ecosystem Services Partnership (www. es-partnership.org/) and the participants at the 2010 Salzau meeting for developing the research agenda 
included here. Parts of this paper benefited from discussions at a meeting in Vienna in November 2009 on Cultural Ecosystem Services organized by Terry Daniel.

\section{References}

I. Costanza R, d'Arge R, de Groot R, Farber S, Grasso M, Hannon B, Limburg K, Naeem S, O'Neill RV, Paruelo J, Raskin RG, Sutton P, van den Belt M: The value of the world's ecosystem services and natural capital. Nature 1997, 387:253-60.

2. Millennium Ecosystem Assessment Board: Living beyond our means-Natural assets and human well-being. United Nations; 2005. [http://www.maweb.org/documents/document.429.aspx.pdf]

3. Boyd J, Banzhaf S: What are ecosystem services? The need for standardized environmental accounting units. Ecol Econ 2007, 63:616-26.

4. Granek EF, Polasky S, Kappel CV, Reed DJ, Stoms DM, Koch EW, Kennedy C], Cramer LA, Hacker SD, Barbier EB, Aswani S, Ruckelshaus M, Perillo GM, Silliman BR, Muthiga N, Bael D, Wolanski E: Ecosystem services as a common language for coastal ecosystem-based management. Conserv Biol 2010, 24:207-16.

5. de Groot RS, Wilson MA, Boumans RMJ: A typology for the classification, description and valuation of ecosystem functions, goods and services. Ecol Econ 2002, 41:393-408.

6. Costanza R, Daly HE: Natural capital and sustainable development. Conserv Biol 1992, 6:37-46.

7. Costanza R, Cumberland JH, Daly H, Goodland R, Norgaard RB: An Introduction to Ecological Economics. Boca Raton, Florida: CRC Press; 1997.

8. Freeman AM 3rd: The Measurement of Environmental and Resource Values: Theories and Methods. 2nd edition. Washington, DC; RFF Press; 2003.

9. Costanza R: Value theory and energy. In Encyclopedia of Energy. Volume 6. Edited by Cleveland CJ. Amsterdam: Elsevier; 2004: 337-346.

10. Haab TC, McConnell KE: Valuing Environmental and Natural Resources: The Econometrics of Non-Market Valuation. Cheltenham, UK: Edward Elgar Publishing Ltd; 2002.

II. Phaneuf DJ, Smith VK, Palmquist RB, Pope JC: Integrating property value and local recreation models to value ecosystem services in urban watersheds. Land Econ 2008, 84:36I-8I.

FI000 Factor 6

Evaluated by Robert Costanza 20 Jun 2011

12. Boardman AE, Greenberg DH, Vining AR, Weimer DL: Cost-Benefit Analysis: Concepts and Practice. 4th edition. Upper Saddle River, NJ: Prentice Hall; 2006.

13. Norton B, Costanza R, Bishop RC: The evolution of preferences: why 'sovereign' preferences may not lead to sustainable policies and what to do about it. Ecol Econ 1998, 24:|93-2||.

14. Barbier EB, Koch EW, Silliman BR, Hacker SD, Wolanski E, Primavera J, Granek EF, Polasky S, Aswani S, Cramer LA, Stoms DM, Kennedy CJ, Bael D, Kappel CV, Perillo GM, Reed DJ: Coastal ecosystem-based management with nonlinear ecological functions and values. Science 2008, 319:32I-3.

FI000 Factor 6

Evaluated by Garry Peterson 10 Jun 2008
15. Koch EW, Barbier EB, Silliman BR, Reed DJ, Perillo GME, Hacker SD, Granek EF, Primavera JH, Muthiga N, Polasky S, Halpern BS, Kennedy CJ, Kappel CV, Wolanski E: Non-linearity in ecosystem services: temporal and spatial variability in coastal protection. Front Ecol Environ 2009, 7:29-37.

FI000 Factor 6

Evaluated by Elena Bennett 25 Mar 2009

16. Costanza R: Social goals and the valuation of ecosystem services. Ecosystems 2000, 3:4-10.

I7. Ehrlich PR, Mooney $\mathrm{H}$ : Extinction, substitution, and ecosystem services. Bioscience 1983, 33:248-54.

FI000 Factor 6

Evaluated by Robert Costanza xx Jun 2011

18. Costanza R, d'Arge R, de Groot R, Farber S, Grasso M, Hannon B, Limburg K, Naeem S, O’Neill RV, Paruelo J, Raskin R, Sutton P, van den Belt M: The value of ecosystem services: putting the issues in perspective. Ecol Econ 1998, 25:67-72.

19. Costanza R: The value of ecosystem services. Ecol Econ 1998, 25: $1-2$.

20. Boumans R, Costanza R, Farley J, Wilson MA, Portela R, Rotmans J, Villa F, Grasso M: Modeling the dynamics of the integrated earth system and the value of global ecosystem services using the GUMBO model. Ecol Econ 2002, 41:529-60.

21. United States Environmental Protection Agency's Science Advisory Board: Valuing the Protection of Ecological Systems and Services: A Report of the EPA Science Advisory Board (EPASAB-09-0 I 2). Washington, DC: EPA; 2009.

22. Polasky S, Segerson K: Integrating Ecology and Economics in the Study of Ecosystem Services: Some Lessons Learned. Annu Rev Resour Econ 2009, I:409-34.

23. Sukhdev P, Wittmer H, Schröter-Schlaack C, Nesshöver C, Bishop J, ten Brink P, Gundimeda H, Kumar P, Simmons B: The Economics of Ecosystems \& Biodiversity (TEEB): Mainstreaming the Economics of Nature: A synthesis of the approach, conclusions and recommendations of TEEB. United Nations Environment Programme; 2010. [http://www.teebweb.org/TEEBSynthesisReport/ tabid/294I0/Default.aspx]

24. Schwartz JD: Should We Put A Dollar Value On Nature? Time Magazine (online edition). March 06, 2010. [http://www.time.com/ time/business/article/0,8599,1970173,00.html]

25. Walsh B: Paying for Nature. Time Magazine (online edition). February 2I, 20II. [http://www.time.com/time/magazine/article/ 0,9171,2048324,00.html]

26. Ecosystem Services for Urbanizing Regions (ESUR)-Integrative Graduate Education and Research Traineeship (IGERT), Portland State University. [www.pdx.edu/esur-igert]

27. The Ecosystem Services Partnership (ESP) homepage. [http:// www.es-partnership.org/]

28. Daily GC, Polasky S, Goldstein J, Kareiva PM, Mooney HA, Pejchar L, Ricketts TH, Salzman J, Shallenberger R: Ecosystem services in decision making: time to deliver. Front Ecol Environ 2009, 7:21-8.

29. Nelson E, Mendoza G, Regetz J, Polasky S, Tallis H, Cameron DR, Chan KMA, Daily GC, Goldstein J, Kareiva PM, Lonsdorf E, Naidoo R, Ricketts TH, Shaw MR: Modeling multiple ecosystem services, biodiversity conservation, commodity production, and tradeoffs at landscape scales. Front Ecol Environ 2009, 7:4-II.

30. Polasky S, Nelson E, Pennington D, Johnson KA: The impact of land-use change on ecosystem services, biodiversity and returns to landowners: a case study in the State of Minnesota. Environ Resourc Econ 2011, 48:219-42. 